\title{
A renal biopsy study in toxaemia of pregnancy
}

\author{
Using routine light and electron microscopy linked with \\ immunofluorescence and immuno-electron microscopy
}

\author{
C. R. TRIBE, G. E. SMART ${ }^{1}$, D. R. DAVIES, AND J. C. MACKENZIE
}

From the Departments of Pathology, Obstetrics, and Nephrology, Southmead Hospital, Bristol, and the Department of Morbid Anatomy, St Thomas's Hospital Medical School, London, UK

SUMMARY Renal biopsy specimens from 11 women with severe pre-eclamptic toxaemia were examined by light and electron microscopy linked with immunofluorescence and immuno-electron microscopy. The part played by the mesangium in causing capillary loop thickening is stressed, and the progress of this 'strangulation' is illustrated. In contrast to the findings of most previous authors, IgM was demonstrated by direct immunofluorescence in all biopsy specimens, and its presence and site within the glomerulus were shown by immuno-electron microscopy in three cases.

The light and electron microscopic features of the renal lesion in toxaemia of pregnancy (pre-eclampsia and eclampsia) have been demonstrated by many authors, and the findings have recently been reviewed by Heptinstall (1974). Thomson et al. (1972) found similar lesions in both toxaemia and abruptio placentae and suggested that the glomerular lesion in these two groups of patients was the result of the response of the endothelial cells and mesangium to deposited fibrin or its derivatives. This hypothesis was supported by early workers using immunofluorescent techniques, which detected fibrin within endothelial and mesangial cells and along the capillary walls (Vassalli et al., 1963; Morris et al., 1964).

The possibility of immunological processes being implicated in the pathogenesis of pre-eclampsia on the basis of renal biopsy studies was raised recently by Petrucco et al. (1974) in Adelaide and by ourselves in Bristol (Tribe et al., 1974). Both renal centres reported the presence of immunoglobulins, especially IgM, within the glomeruli. In view of this new evidence for immunoglobulin deposition and its possible implications concerning the pathogenesis of pre-eclampsia, it seemed important both to verify the presence and localise the site of IgM deposition using the recently developed technique of immuno-electron microscopy (Davies et al., 1977). We now present the findings in renal biopsies

${ }^{1}$ Present address: Simpson Memorial Maternity Pavilion, Edinburgh.

Received for publication 8 January 1979 undertaken in the early puerperium in 11 patients with pre-eclampsia.

\section{Patients and methods}

\section{PATIENTS}

During a period of one year we studied 11 pregnant women who developed severe pre-eclamptic toxaemia (PET), defined as a diastolic blood pressure of $90 \mathrm{mmHg}$ or greater accompanied by proteinuria of $0.5 \mathrm{~g} / 24 \mathrm{~h}$ or more with or without oedema. Several of the cases had unusual clinical features, which are detailed in Table 1 together with the results of laboratory investigations.

\section{RENAL BIOPSY TECHNIQUE}

Percutaneous renal biopsies were performed in the early puerperium between two and 17 days after delivery, the average time being nine days postpartum. Specimens were obtained using a Tru-Cut disposable biopsy needle under local anaesthesia with the patient in the prone position. Concurrent excretory urography and image intensification allowed accurate localisation of the kidney and placing of the biopsy needle. Apart from transient mild haematuria there were no complications.

\section{Methods}

HISTOPATHOLOGY

\section{Light microscopy}

The biopsy specimens were fixed in $10 \%$ buffered 681 
Table 1 Clinical and laboratory details

\begin{tabular}{|c|c|c|c|c|c|c|c|c|c|}
\hline Case & Age & Parity & $\begin{array}{l}\text { Time of biopsy } \\
\text { after delivery } \\
\text { (days) }\end{array}$ & $\begin{array}{l}\text { Gestation } \\
\text { (weeks) }\end{array}$ & $B P \max$ & $\begin{array}{l}\text { Max blood } \\
\text { urea* } \\
(\mathrm{mg} / 100 \mathrm{ml})\end{array}$ & $\begin{array}{l}\text { Serum uric } \\
\text { acid }^{*} \\
(\mathrm{mg} / 100 \mathrm{ml})\end{array}$ & $\begin{array}{l}\text { Lowest creatinine } \\
\text { clearance }(\mathrm{ml} / \mathrm{min})\end{array}$ & Proteinuria $(g / 24 h)$ \\
\hline 1 & 23 & $0 \div 0$ & 8 & 39 & $175 / 110$ & 29 & $4 \cdot 5$ & 66 & $1 \cdot 5$ \\
\hline 2 & 25 & $1: 0$ & 9 & 36 & $200 / 120$ & 36 & $3 \cdot 5$ & 102 & $1 \cdot 0$ \\
\hline 3 & 23 & $0 \cdot 0$ & 12 & 34 & $170 / 110$ & 23 & $4 \cdot 1$ & 140 & $4 \cdot 0$ \\
\hline 4 & 27 & $0+0$ & 3 & 22 & $170 / 110$ & 32 & $5 \cdot 9$ & 79 & $10 \cdot 0$ \\
\hline 5 & 21 & $0 \div 0$ & 7 & 38 & $200 / 140$ & 32 & NA & 54 & 0.5 \\
\hline 6 & 47 & $0: 0$ & 14 & $? 36$ & $180 / 115$ & 44 & $6 \cdot 3$ & 73 & $3 \cdot 0$ \\
\hline 7 & 25 & $0: 0$ & 12 & 24 & $180 / 110$ & 30 & NA & 26 & $\begin{array}{r}1.0 \\
+\quad+\end{array}$ \\
\hline 8 & 28 & $0+0$ & 15 & $27+$ & $150 / 110$ & 91 & $7 \cdot 9$ & 25 & $2 \cdot 0$ \\
\hline 9 & 31 & $0+0$ & 6 & 30 & $160 / 110$ & 25 & $7 \cdot 8$ & 86 & $3 \cdot 5$ \\
\hline 10 & 31 & $1+0$ & 17 & 28 & $160 / 90$ & 81 & $7 \cdot 0$ & 66 & $2 \cdot 0$ \\
\hline 11 & 22 & $0+0$ & 15 & 32 & $160 / 110$ & 47 & $4 \cdot 6$ & 66 & $1 \cdot 0$ \\
\hline
\end{tabular}

$\mathrm{NA}=$ not available $; \mathrm{FD}=$ forceps delivery $;$ Ass $\mathrm{Br}=$ assisted breech $; \mathrm{CS}=$ Caesarean section; Abn = abortion; SVD = spontaneous vertex delivery $\mathbf{N W}=$ not weighed; $\mathbf{A}=$ alive; $\mathbf{S B}=$ stillborn; IUD = intrauterine death $; \mathrm{FDP}=$ fibrin degradation products.

*Conversion: Traditional to SI units-Blood urea: $1 \mathrm{mg} / 100 \mathrm{ml} \approx 0 \cdot 17 \mathrm{mmol} / 1$ (normal range $2 \cdot 5-7 \cdot 5 \mathrm{mmol} / 1$ )

Serum uric acid: $1 \mathrm{mg} / 100 \mathrm{ml} \approx 0.06 \mathrm{mmol} / 1$ (normal range $0.2-0.45 \mathrm{mmol} / \mathrm{l}$ )

neutral formalin, and paraffin sections were cut at $3 \mu \mathrm{m}$ and stained routinely with haematoxylin and eosin (H and $\mathrm{E})$, van Gieson elastic (VGE), periodic acid schiff (PAS), and periodic acid-silver methenamine (PASM).

\section{Electron microscopy}

Specimens were fixed in $1 \%$ osmium tetroxide, dehydrated, and embedded in epoxy resin (Durcopan). Sections were cut at $500 \AA$ using an LKB ultramicrotome, stained with uranyl acetate and lead citrate, and examined with a Philips 201 electron microscope.

\section{Immunohistology}

The specimens were snap-frozen with liquid nitrogen. Direct immunofluorescence studies were performed on $4 \mu \mathrm{m}$ cryostat cut sections picked up on to previously prepared Teflon-coated slides, five sections per slide and dried for 1 hour. The sections were stained with FITC-labelled antisera to IgG, IgA, IgM, fibrin/fibrinogen, and the $\mathrm{C} 3$ component of complement (Wellcome Reagents and Hoechst Pharmaceuticals) using controls as described by Davies et al. (1973). These were examined and graded by two observers using a Wild M20 microscope with blue light fluorescence.

IMMUNO-ELECTRON MICROSCOPY

In three cases $(3,10$, and 11) frozen tissue was available after immunofluorescence for immunoelectron microscopy studies.

These were carried out according to the method described by Davies et al. (1977): $40 \mu \mathrm{m}$ frozen sections were cut, fixed in $4 \%$ buffered methanol-free formalin, and after prolonged immersion in buffer treated with peroxidase-labelled antisera (Dakopatts). HRP-labelled anti-human IgG, IgM, and $\operatorname{IgA}$ (heavy chain specific) were used in dilutions varying between $1 / 2$ and 1/16. After further immersion in buffer the HRP was developed with diaminobenzidene tetrahydrochloride and hydrogen peroxide in buffer (Graham and Karnovsky, 1966). Fixation in Palade's sucrose was followed by processing to Epon. $1 \mu \mathrm{m}$ sections were examined by light microscopy and ultrathin sections by electron microscopy without further staining.

\section{Controls}

Sections treated with unlabelled antisera were also processed in the same way. Tissue from patients with other renal diseases were treated with the same reagents. The antisera were examined by immunoelectrophoresis.

\section{Results (summarised in Table 2)}

Renal tissue was available for light microscopy in all 11 cases. Only one glomerulus was found in case 8 , but between four and 40 glomeruli were present in all the other specimens. This allowed simple grading of the changes into mild, moderate, severe, and very severe.

\section{LIGHT MICROSCOPICAL CHANGES}

The appearances were similar to those described by Sheehan and Lynch (1973) and Heptinstall (1974). The abnormalities are largely confined to the glomeruli and include:

(a) Involvement of all glomeruli.

(b) Enlargement of the glomeruli.

(c) An increase in the number of cells in the tuft. 


\begin{tabular}{|c|c|c|c|c|c|}
\hline \multirow{2}{*}{$\begin{array}{l}\text { um } F D P \\
r \text { mal range } \\
0 \mathrm{\mu} / \mathrm{ml})\end{array}$} & \multirow{2}{*}{$\begin{array}{l}\text { Mode of } \\
\text { delivery }\end{array}$} & \multicolumn{2}{|c|}{ Child } & \multirow{2}{*}{$\begin{array}{l}\text { Outcome of } \\
\text { pregnancy }\end{array}$} & \multirow[t]{2}{*}{ Clinical details } \\
\hline & & $\operatorname{Sex}$ & Weight $(k g)$ & & \\
\hline & $\begin{array}{l}\text { FD } \\
\text { Ass Br } \\
\text { CS } \\
\text { Abn } \\
\text { CS }\end{array}$ & $\begin{array}{l}\mathbf{F} \\
\mathbf{F} \\
\mathbf{M} \\
\mathbf{F} \\
\mathbf{M}\end{array}$ & $\begin{array}{l}3 \cdot 33 \\
2 \cdot 10 \\
2 \cdot 19 \\
\text { NW } \\
\text { NW }\end{array}$ & $\begin{array}{l}\text { A } \\
\text { A } \\
\text { A } \\
\text { Abn } \\
\text { A }\end{array}$ & $\begin{array}{l}\text { Fulminating PET } \\
\text { Severe PET } \\
\text { Severe PET on pre-existing essential hypertension } \\
\text { Molar placenta and co-existing fetus (both triploid) } \\
\text { Fulminating PET }\end{array}$ \\
\hline & $\begin{array}{l}\mathrm{CS} \\
\mathrm{Abn}\end{array}$ & $\begin{array}{l}\mathbf{M} \\
\mathbf{M}\end{array}$ & $\begin{array}{l}2 \cdot 20 \\
0.53\end{array}$ & $\begin{array}{l}\text { A } \\
\text { bn }\end{array}$ & $\begin{array}{l}\text { Severe PET } \\
\text { Fulminating PET at } 24 \text { weeks. Placenta infarcted with mild hydropic changes } \\
\text { (normal karyotype) }\end{array}$ \\
\hline & $\begin{array}{l}\text { Abn } \\
\text { CS } \\
\text { SVD }\end{array}$ & $\begin{array}{l}\mathbf{M} \\
\mathbf{M} \\
\mathbf{F}\end{array}$ & $\begin{array}{l}\text { NW } \\
1 \cdot 29 \\
1 \cdot 0\end{array}$ & $\begin{array}{l}\text { Abn } \\
\text { A } \\
\text { SB }\end{array}$ & $\begin{array}{l}\text { PET associated with acute on chronic pyelonephritis } \\
\text { Fulminating PET } \\
\text { PET from } 24 \text { weeks. APH at } 28 \text { weeks with IUD. Postpartum eclampsia. } \\
\text { Micro-angiopathic haemolytic anaemia }\end{array}$ \\
\hline & CS & $\mathbf{F}$ & $1 \cdot 5$ & $\mathbf{A}$ & Antepartum eclampsia. Unbooked patient \\
\hline
\end{tabular}

with some lobulation in the severe cases. Swelling of the cytoplasm of the endothelial cells, which reduces the capillary lumina and may obliterate them in severe cases. This makes the glomeruli characteristically bloodless and led to the term 'endotheliosis' in the early literature.

(d) A probable increase in mesangial cells and matrix.

(e) Small amounts of fibrin can usually be demonstrated.

$(f)$ The capillary basement membranes are usually reported as of normal thickness, but in severe cases thickening occurs, which may mimic membranous or membranoproliferative glomerulonephritis.

All these changes were found in the renal biopsy specimens from our 11 patients apart from our failure to demonstrate fibrin. The changes varied in severity from case to case, four cases showing mild, three moderate, three severe, and one very severe abnormalities. Figures 1 and 2 illustrate these findings, and we stress the abnormalities seen on PASM sections in this severe case. It showed a well-marked splitting of the capillary loops, producing a 'tramlining effect' very similar to that found in membranoproliferative glomerulonephritis but without any marked mesangial increase.

\section{ULTRASTRUCTURAL CHANGES}

Glomerular tissue was studied by electron microscopy in all 11 cases. This was usually restricted to portions of one or two glomeruli.

Our findings mirrored fairly accurately those found on light microscopy, with three cases graded mild, three cases moderate, four cases severe, and one very severe. The changes agreed broadly with those described by other authors (Heptinstall, 1974), but our interpretation of the part played by

Table 2 Histology results

\begin{tabular}{|c|c|c|c|c|c|c|c|c|c|}
\hline \multirow[t]{2}{*}{ Case } & \multirow[t]{2}{*}{ Age } & \multirow{2}{*}{$\begin{array}{l}\text { No. of } \\
\text { glomeruli }\end{array}$} & \multicolumn{2}{|l|}{ Microscopy } & \multicolumn{3}{|c|}{ Direct immunofluorescence ${ }^{*}$} & \multirow[b]{2}{*}{ Fibrin } & \multirow[b]{2}{*}{ Complement } \\
\hline & & & Light & Electron & $I g G$ & $\operatorname{Ig} A$ & $I g M$ & & \\
\hline $\begin{array}{r}1 \\
2 \\
3 \\
4 \\
5 \\
6 \\
7 \\
8 \\
9 \\
10 \\
11\end{array}$ & $\begin{array}{l}23 \\
25 \\
23 \\
27 \\
21 \\
47 \\
25 \\
28 \\
31 \\
31 \\
22\end{array}$ & $\begin{array}{r}15 \\
12 \\
16 \\
40 \\
4 \\
20 \\
20 \\
1 \\
6 \\
10 \\
6\end{array}$ & $\begin{array}{l}\text { Mild } \\
\text { Mild } \\
\text { Severe } \\
\text { V. severe } \\
\text { Mild } \\
\text { Moderate } \\
\text { Severe } \\
\text { Moderate } \\
\text { Severe } \\
\text { Moderate } \\
\text { Mild }\end{array}$ & $\begin{array}{l}\text { Mild } \\
\text { Severe } \\
\text { Severe } \\
\text { V. severe } \\
\text { Mild } \\
\text { Mild } \\
\text { Severe } \\
\text { Moderate } \\
\text { Severe } \\
\text { Moderate } \\
\text { Moderate }\end{array}$ & $\begin{array}{l}\overline{ \pm} \\
\overline{-} \\
\overline{ \pm} \\
\overline{-} \\
\overline{-} \\
\overline{-} \\
-\end{array}$ & $\begin{array}{l} \pm \\
+ \\
\pm \\
\pm \\
\pm \\
\pm \\
+ \\
- \\
-\end{array}$ & $\begin{array}{l}++ \\
++ \\
+++ \\
+++ \\
+++ \\
++ \\
+++ \\
++ \\
+ \\
+ \\
++\end{array}$ & $\begin{array}{l}+ \\
+ \\
+ \\
+ \text { Focal } \\
+ \text { Focal } \\
- \\
+ \\
+ \text { Mesangial } \\
- \\
-\end{array}$ & $\begin{array}{l}\overline{-} \\
\overline{-} \\
\overline{+} \\
\overline{+}(\mathrm{V}) \\
+(\mathrm{V}) \\
\overline{+}(\mathrm{V}) \\
++(\mathrm{V})\end{array}$ \\
\hline
\end{tabular}

* Graded by two observers on arbitary scale by intensity of staining (from - (negative) to,,, \pm+++ and +++ ).

$\mathbf{V}=$ vascular 


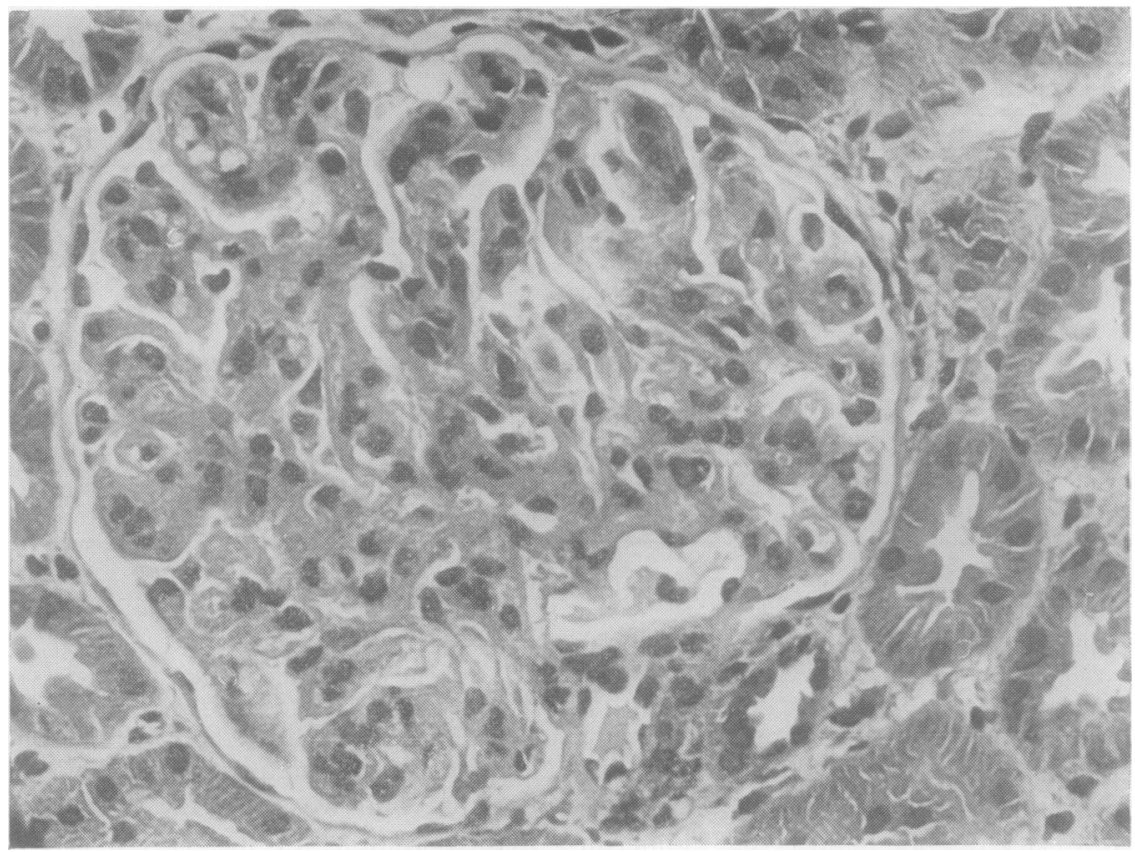

Fig. 1 Light microscopy: (a) Representative glomerulus in case 4. Note increase in endothelial and mesangial cells with compression of the capillaries ('endotheliosis') and a tendency to lobulation. The capillary loops appear thickened and these appearances mimic membranoproliferative glomerulonephritis. Haematoxylin and eosin $\times 845$.

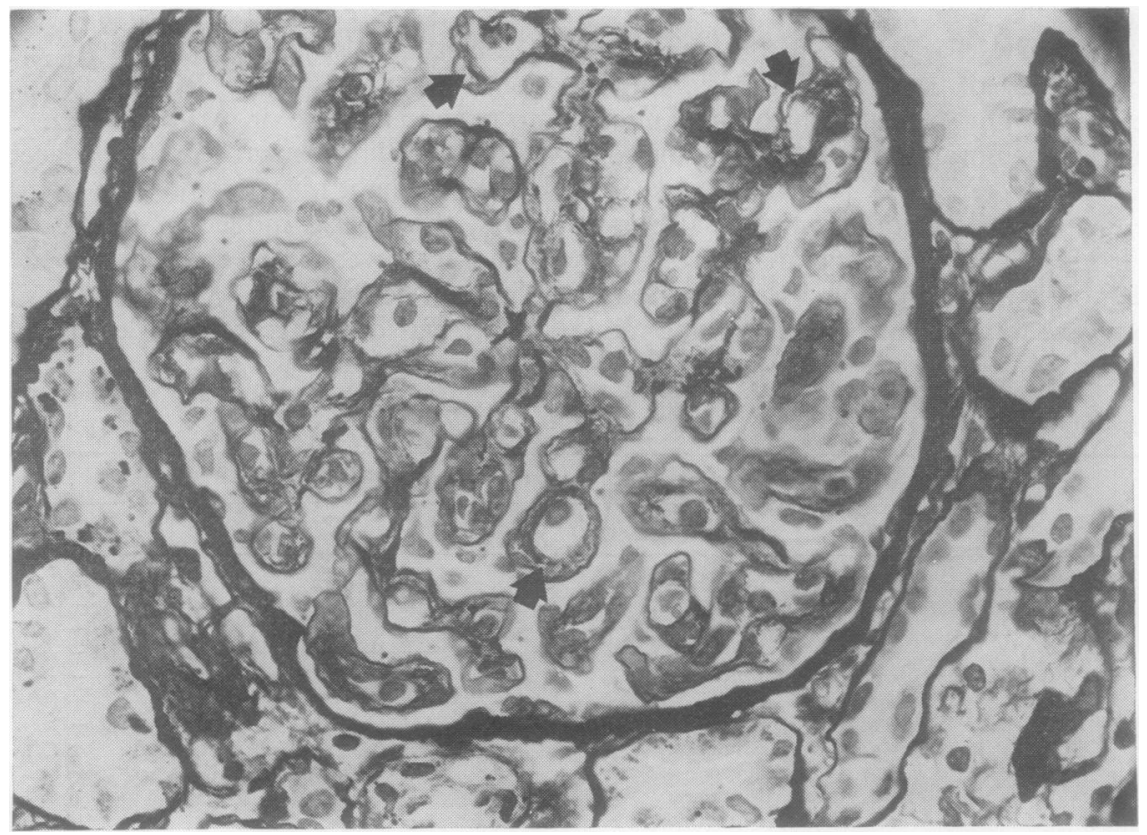

Fig. 2 Light microscopy: (b) Glomerulus from case 4 stained by PASM to show the double contouring ('tramlining') of the capillary loops (arrowed) in the renal biopsies from severe cases of pre-eclamptic toxaemia. $\times 1055$. 


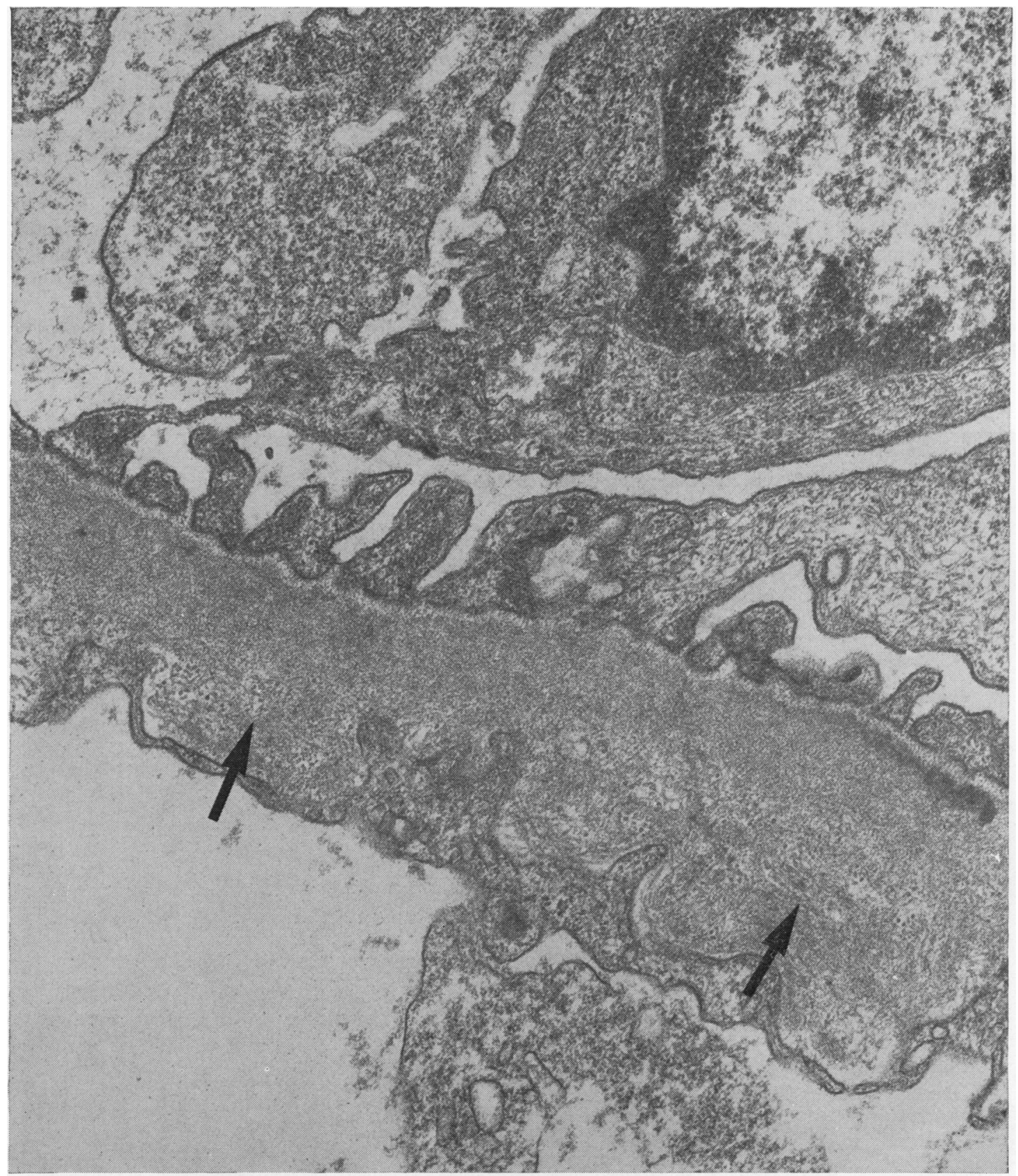

Fig. 3 Ultrastructure I. Electron micrograph illustrating the earliest changes found in the basement membranes of the capillaries. Note the irregular expansion of the lamina rara interna by loosely woven fibrillary material (arrowed). The foot processes are preserved. Lead citrate and uranyl acetate (LC and UA). $\times 37600$. 
the mesangium in the basement membrane thickening differs from that of other authors and will be described in detail.

In 10 of the biopsy specimens there was good preservation of the epithelial foot processes. In one case (4) there was extensive foot process fusion; interestingly, this patient had the largest protein leak $(10 \cdot 0 \mathrm{~g} / 24 \mathrm{~h})$.

There was variable proliferation of the endothelial cells and a less marked increase in the mesangial cells and matrix.

In the severest cases lipid droplets were found both in the epithelial cell cytoplasm and in the thickened basement membranes.

The basement membranes were variably thickened in all cases but with preservation of some loops of normal calibre in even the most severely diseased glomeruli. The mildest changes (Fig. 3) were focal, irregular expansion of the lamina rara interna by loosely woven fibrillary material. Sometimes the expansion had translucent areas, and small islands of endothelial cytoplasm were isolated in the thickened zone (Fig. 4). In other cases this zone included probable small lipid droplets.

In cases with moderate changes, it became apparent that the widening of the lamina rara interna was greatest at the mesangial aspect of the loop. It was also evident that mesangial cell cytoplasm was extending around the capillary loops, forming a 'double contour' akin to the process seen in mesangiocapillary (membranoproliferative) glomerulonephritis (Fig. 4). This ultrastructural change explains the 'tramlining' seen on the silver-stained light microscopical sections (Fig. 2).

In nearly all cases there were areas in the thickened loops which showed subendothelial electron dense

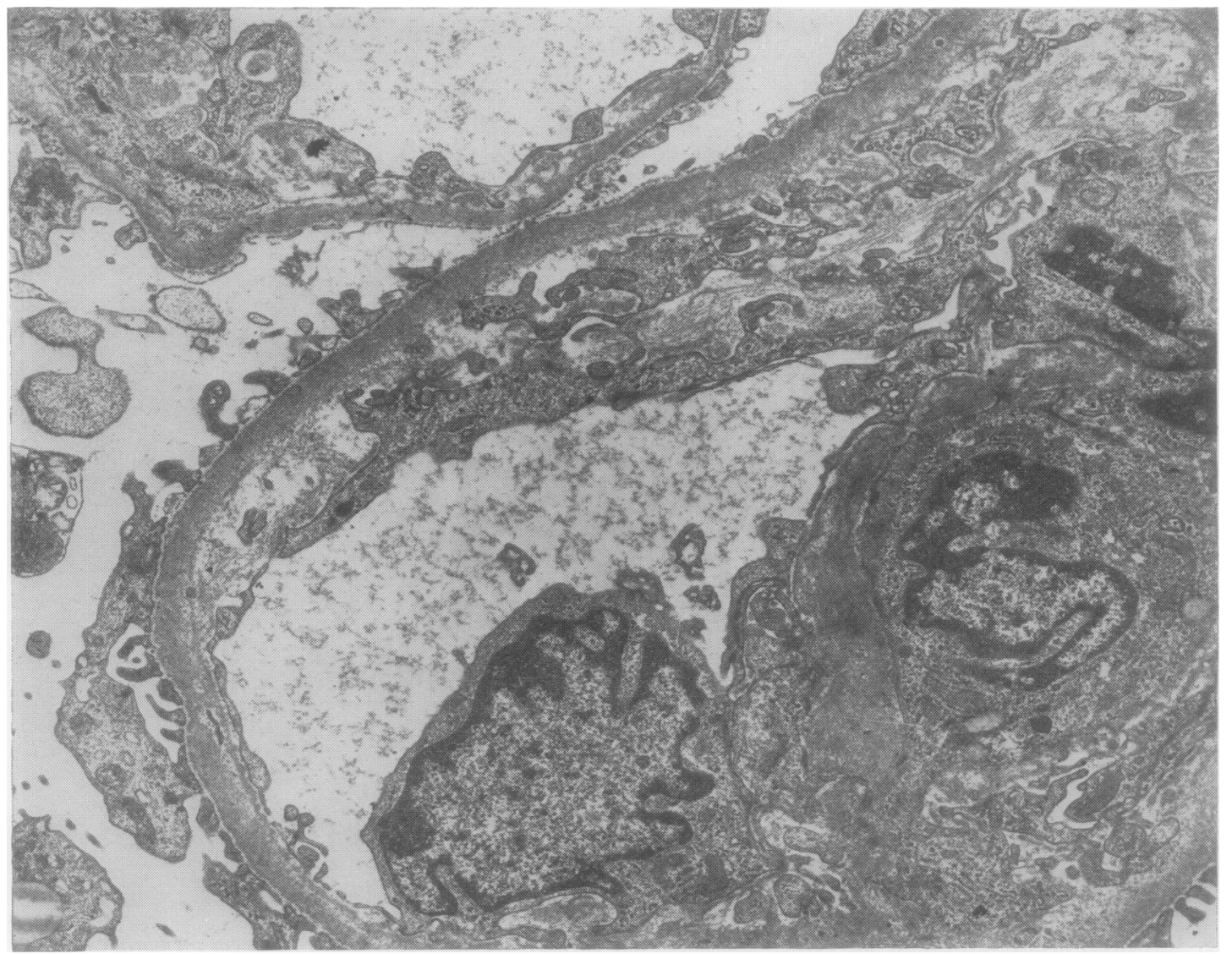

Fig. 4 Ultrastructure II. Low-power electron micrograph illustrating progression of basement membrane changes. The expanded lamina rara interna shows translucent areas, and mesangial cytoplasm is starting to extend around the capillary loop, leaving islands of isolated endothelial cytoplasm. LC and UA $\times 10600$. 


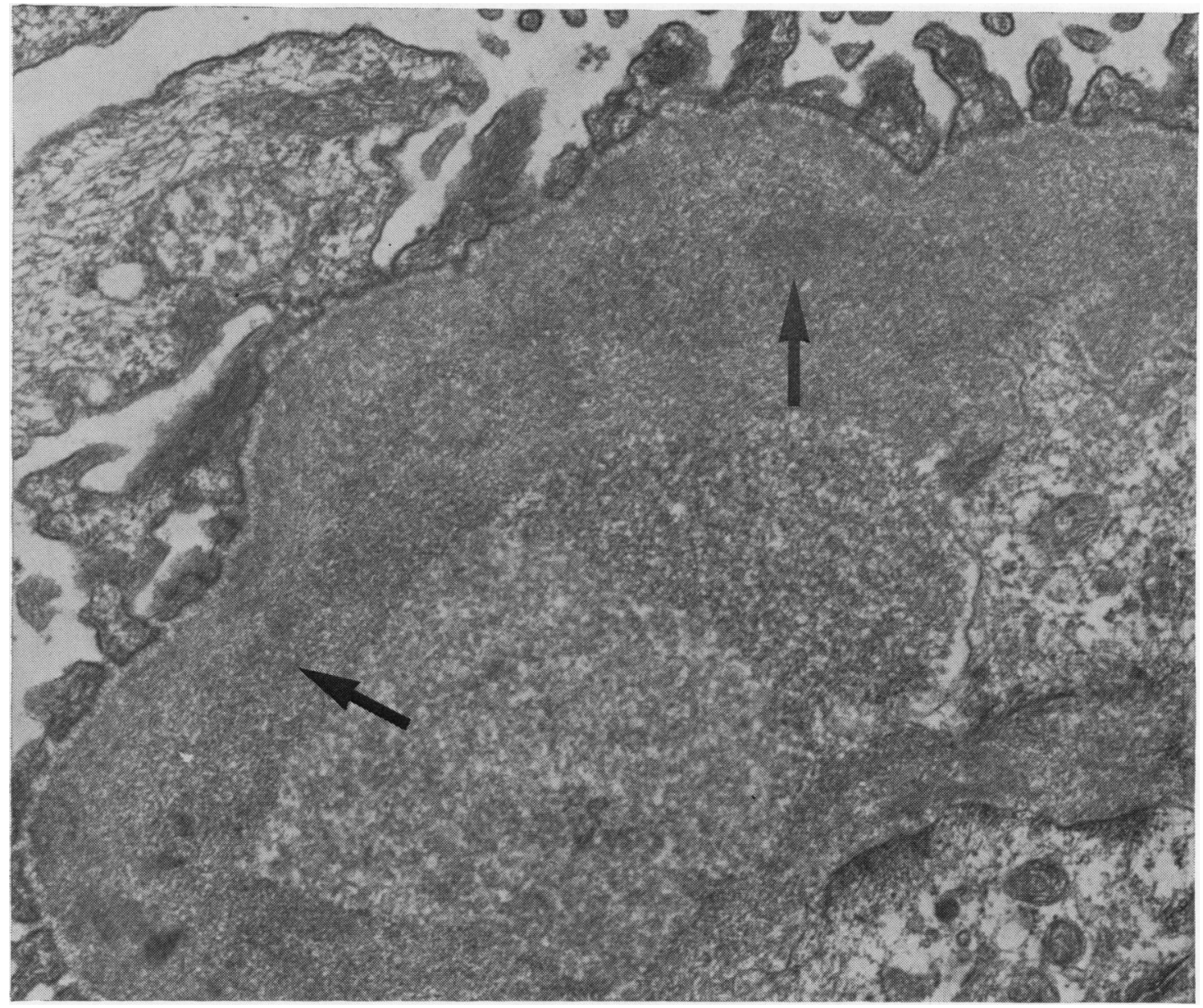

Fig. 5 Ultrastructure III. A segment of duplicated thickened capillary loop showing granular subendothelial electron dense deposits (arrowed). Compare with the immuno-electron microscopic findings in Figs 8 and 9. LC and UA $\times 35400$.

deposits (Fig. 5). It is of great interest that it is in these areas that $\operatorname{IgM}$ was found on immuno-electron microscopy (Figs 8 and 9).

In the severest cases the capillary lumina were virtually obliterated by mesangial tissue, which has extended completely round the inner walls of the loops, a process often referred to as 'mesangial strangulation'. Figure 6 illustrates our severest case, in which a squashed red blood cell fills the grossly narrowed lumen surrounded by a double contour thickened membrane at least $10 \times$ normal width. No obvious fibrillary fibrin was identified in any of the specimens.

IMMUNOFLUORESCENT FINDINGS

Adequate renal tissue, including two or more glomeruli, was available in all 11 patients for direct immunofluorescent studies, and the results are summarised in Table 2.

The heavy and extensive staining for IgM was the most striking finding in these specimens. This was basically finely granular in nature although some areas looked linear. The deposition, which was discontinuous, involved all glomeruli but was irregular and spared some segments of the glomerular tufts. It involved the peripheral loops, and there were some foci in mesangial areas. This pattern of IgM deposition is illustrated in Figure 7. In four cases this was graded +++ , in a further five cases ++ , and in only two cases + .

Traces $( \pm)$ of IgG were found in two cases and traces $( \pm)$ of small amounts of IgA were found in 


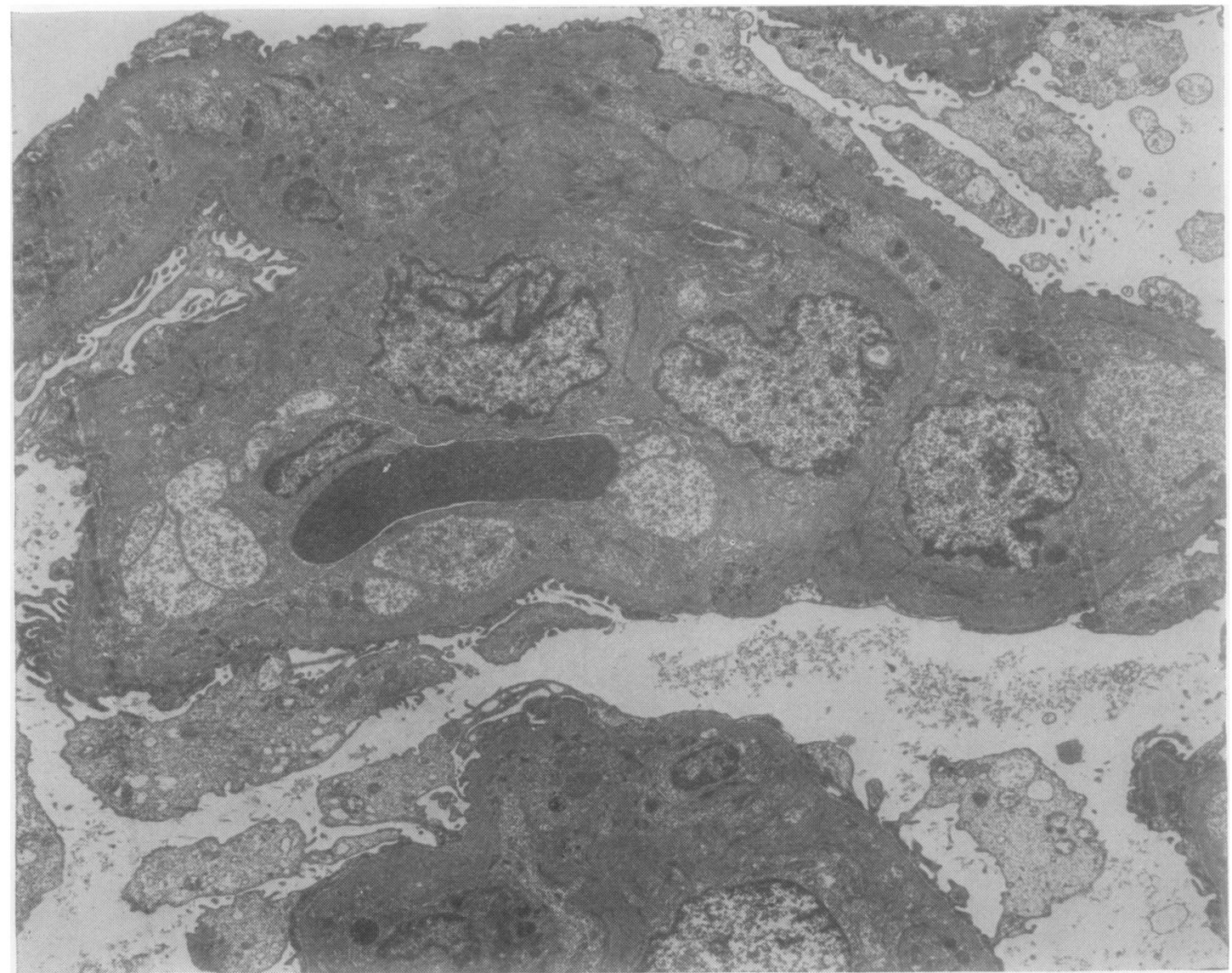

Fig. 6 Ultrastructure IV. Low-power electron micrograph from the severest case (4). There is now marked narrowing of the capillaries by grossly thickened double-contoured basement membranes. The foot processes are mainly fused. $L C$ and $U A \times 5000$.

six cases. In all instances these were segmental and usually confined to the mesangium.

Especial attention was paid to the deposition of fibrin since earlier authors (Vassalli et al., 1963; Thomson et al., 1972) had reported large amounts of fibrin or fibrinogen derivatives in the glomeruli of pre-eclamptic patients. In marked contrast to the findings of these workers, only small amounts of fibrin were detected in 7 of our 11 biopsy specimens. In all cases the fluorescence was segmental and mesangial in site.

Complement (C3) was detected in the glomerular arterioles of four patients and was found only once in the glomeruli.

IMMUNO-ELECTRON MICROSCOPY

All three cases showed deposits of IgM. The deposits were widespread in one case (3) but were more limited in distribution in the other two. The deposits were localised in the subendothelial region but did not fill the entire abnormal areas between endothelial cell and lamina densa (Figs 8 and 9). No deposits stained for IgG or IgA or with unlabelled serum. Lipid droplets (extracellular and intracellular) were electron dense in all these control sections as they all had been osmicated.

\section{Discussion}

Our findings on light microscopy broadly agree with those of previous authors, with the exception of the 'tramlining' effect seen in the silver-stained sections from the most severe cases. This striking picture, illustrated in Fig. 2, was reported by Kincaid-Smith in 1975, and she comments that it differs from mesangiocapillary glomerulonephritis only in that 


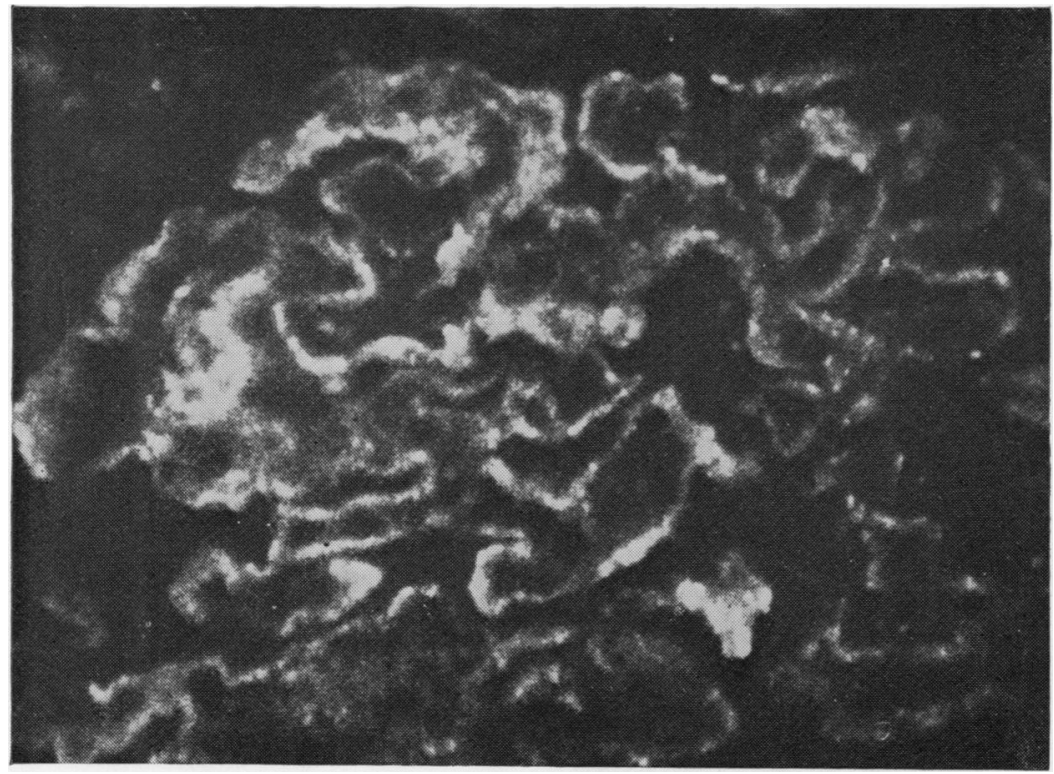

Fig. 7 Immunofluorescence.

Case 3. The pattern of IgM deposition in the glomerulus is shown. This is finely granular and discontinuous and involves the capillary loops with some foci in the mesangium. FITC-labelled rabbit anti-human IgM $\times 510$.

the glomeruli show less proliferation. She thought this double contour or apparent duplication of the basement membrane represented organisation of subendothelial deposits of fibrin and illustrates cases with masses of granular and fibrillary fibrin in the subendothelial zone. We believe that mesangial interposition and IgM deposition also play a part and were the most important features causing basement membrane duplication in our post-partum specimens.

Our ultrastructural findings are also largely in accord with those of other authors. These have been recently reviewed by Dunnill (1976), and it is only necessary to comment on certain aspects in the literature. As early as 1964 Altcheck, in a study of renal biopsies in 100 patients with toxaemia of pregnancy, thought the renal glomerular lesion was pathognomonic. The lesion, as he described it, consisted of swelling of the cytoplasm of the endothelial cell, deposits underneath the basement membrane and within the swollen endothelial cytoplasm, and an increase in intercapillary cells. These stream out of the intercapillary areas and insinuate their cytoplasm between the endothelial cells and the basement membranes. This latter finding, with the modern terminology of 'mesangial' rather than 'intercapillary' cells, is the outstanding ultrastructural feature in our series and has not been stressed by other workers. Most authors, including Pirani et al. (1963) and Thomson et al. (1972), thought that the subendothelial deposits were derived from fibrinogen and used this evidence to support the concept that intravascular coagulation is concerned in pre-eclampsia. Further evidence for an abnormal state of intravascular coagulation was provided by Vassalli et al. (1963) and Fiaschi and Naccarato (1968), who demonstrated fibrin or fibrinogen by immưnofluorescent techniques in the glomeruli of pre-eclamptic patients. Both these workers also found smaller amounts of gammaglobulin or IgG.

In 1974, however, Petrucco et al. were able to demonstrate both IgM and IgG in 11 renal biopsies from patients with pre-eclampsia and suggested that an immunological mechanism may be responsible for the renal lesions in pre-eclampsia.

The main immunological difference between our observations and those of earlier workers was plentiful IgM deposits and little fibrin in our biopsy tissue, in contrast to marked fibrin with little or no immunoglobulin in other series. It is not clear whether IgM was looked for in some of the earlier studies. If IgM really was absent, then a possible explanation may be the timing of the biopsies in relation to delivery; ours were taken in the post-partum period whereas some others were taken before delivery.

The granularity of the IgM deposits, both by direct immunofluorescence and at electron microscopy, is in itself strong evidence of immune complex deposition. The immuno-peroxidase studies show that the IgM deposits are present in the subendothelial area, which communicates with the mesangium and from which deposits may be cleared. This 

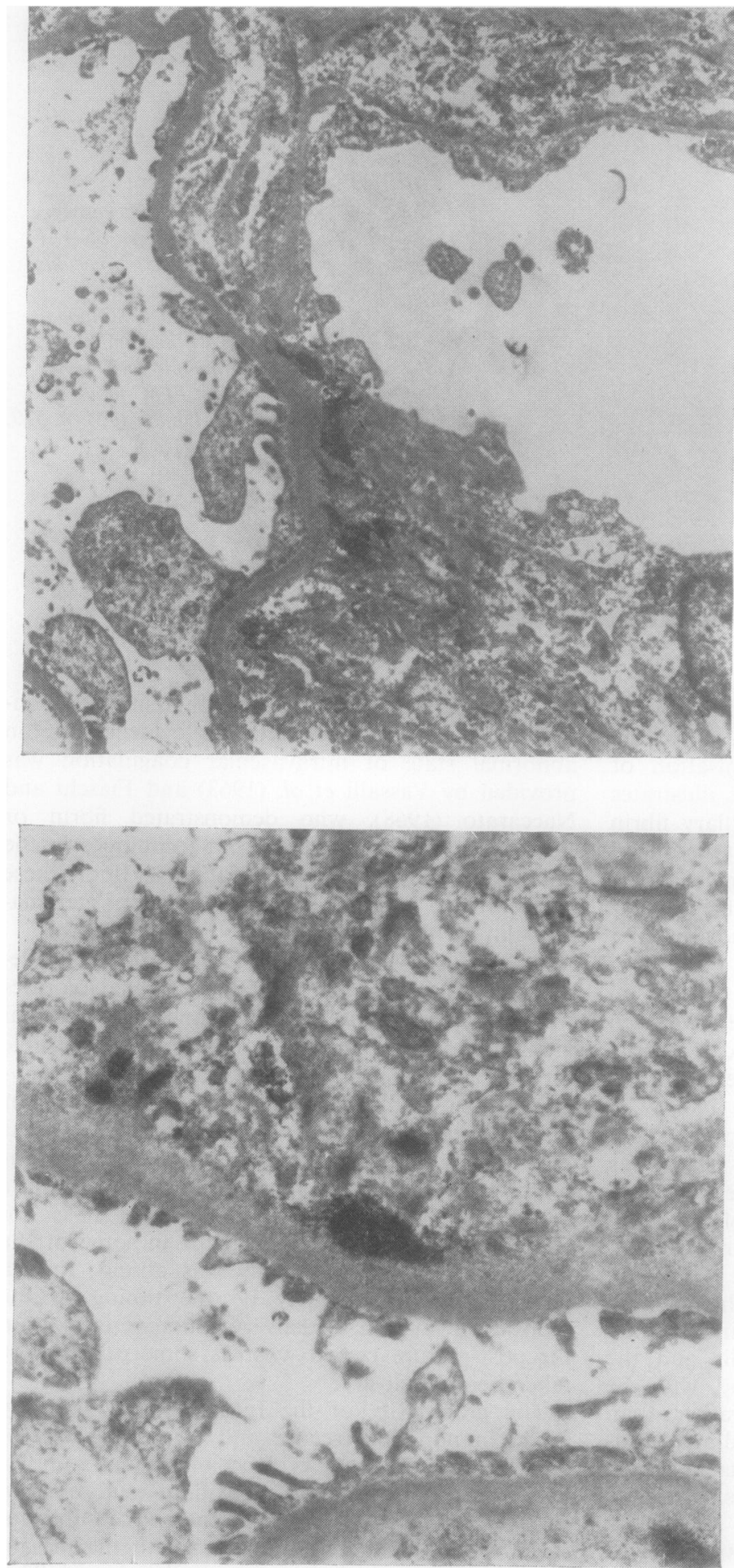

Figs 8 and 9 Immuno-electron microscopy. Case 3. Dense granular deposits can be seen lying in the subendothelial pararesangial regions. Horse-radish peroxidase labelled anti-human IgM. $\times 5200$ and 11900. 
is the zone that Germuth and Rodriguez (1973) have shown to be the site of deposition of large antigen-antibody complexes in experimental immune complex disease and is the site where one would expect to find IgM complexes.

The presence of deposits of immunoglobulin does not necessarily signify an immune complex disease. IgM has been demonstrated in advanced glomerular disease of non-immune origin (Berger et al., 1971; Velosa et al., 1976) and also in focal glomerular sclerosis and minimal change glomerulonephritis, where an immune complex origin has not been demonstrated (Prasad et al., 1977; Sherman et al., 1977). In order to establish whether the IgM is present with an antigen it would be necessary to identify its specificity, but we have not done this. It is, however, possible that the deposits represent the presence of pathological immune complexes resulting from an immunological reaction to trophoblastic antigens. Direct evidence for this does not exist, but it has been reported that circulating immune complexes are more frequent in preeclamptic toxaemia than in normal pregnancies (Thomson et al., 1976; Stirrat et al., 1978).

An alternative explanation is to postulate that the IgM occurs secondarily to the laying down of fibrin or fibrinogen products in the glomeruli which has been described frequently by other authors. The presence of $\mathrm{IgM}$ in this condition is irrefutable, but it does require explanation. It seems likely to prove to be a secondary phenomenon, but it may hold the key to the pathogenesis of the disease.

We thank Professor H. G. Dixon for permission to include patients under his care in this study. We also thank Mr Brian Amer for invaluable technical and photographic assistance, Miss Beryl Evans for technical help with the immuno-electron microscopy, and Miss Carol Jenkins for secretarial aid.

\section{References}

Altcheck, A. (1964). Renal biopsy and its clinical correlation in toxaemia of pregnancy. Circulation, 30, Supplement II, 43-51.

Berger, J., Yaneva, H., and Hinglais, N. (1971). Immunohistochemistry of glomerulonephritis. Advances in Nephrology, I, 11-30.

Davies, D. R., Tighe, J. R., Jones, N. F., and Brown, G. W. (1973). Recurrent haematuria and mesangial IgA deposition. Journal of Clinical Pathology, 26, 672-677.

Davies, D. R., Tighe, J. R., Wing, A. J., and Jones, N. F. (1977). Immunoglobulin deposition in membranous glomerulonephritis: immunofluorescence and immunoelectron microscopy findings. Histopathology, 1 , 39-52.
Dunnill, M. S. (1976). Pathological Basis of Renal Disease, pp. 252-261. W. B. Saunders, London.

Fiaschi, E., and Naccarato, R. (1968). The histopathology of the kidney in toxaemia. Serial renal biopsies during pregnancy, puerperium and several years post partum. Virchows Archiv, Abteilung A Pathologische Anatomie, 345, 299-309.

Germuth, F. G., and Rodriguez, E. (1973). Immunopathology of the Renal Glomerulus, pp. 15-43. Little, Brown, Boston.

Graham, R. C., and Karnovsky, M. J. (1966). The early stages of absorption of injected horseradish peroxidase in the proximal tubules of mouse kidney: ultrastructural cytochemistry by a new technique. Journal of Histochemistry and Cytochemistry, 14, 291-302.

Heptinstall, R. H. (1974). Pathology of the Kidney, 2nd edition, pp. 715-736. Little, Brown, Boston.

Kincaid-Smith, P. (1975). The Kidney; A Clinico-Pathological Study, pp. 230-233. Blackwell, Oxford.

Morris, R. H., Vassalli, P., Beller, F. K., and McCluskey, R. T. (1964). Immunofluorescent studies of renal biopsies in the diagnosis of toxemia of pregnancy. Obstetrics and Gynaecology, 24, 32-46.

Petrucco, O. M., Thomson, N. M., Lawrence, J. R., and Weldon, M. W. (1974). Immunofluorescent studies in renal biopsies in pre-eclampsia. British Medical Journal, 1, 473-476.

Pirani, C. L., Pollak, V. E., Lannigan, R., and Polli, G. (1963). The renal glomerular lesions of pre-eclampsia; electron microscopic studies. American Journal of Obstetrics and Gynaecology, 87, 1047-1070.

Prasad, D. R., Zimmerman, S. W., and Burkholder, P. M. (1977). Immunohistologic features of minimalchange nephrotic syndrome. Archives of Pathology and Laboratory Medicine, 101, 345-349.

Sheehan, H. L., and Lynch, J. B. (1973). Pathology of Toxaemia of Pregnancy. Churchill, Livingstone, Edinburgh and London.

Sherman, R., Susin, M., and Mouradian, J. (1977). Focal glomerularsclerosis. In Seminars in Nephrology, (Perspectives in Nephrology and Hypertension), edited by E. L. Becker. John Wiley, Chichester.

Stirrat, G. M., Redman, C. W. G., and Levinsky, R. J. (1978). Circulating immune complexes in pre-eclampsia. British Medical Journal, 1, 1450-1451.

Thomson, D., Paterson, W. G., Smart, G. E., Macdonald, M. K., and Robson, J. S. (1972). The renal lesions of toxaemia and abruptio placentae studied by light and electron microscopy. Journal of Obstetrics and Gynaecology of the British Commonwealth, 79, 311-320.

Thomson, N. C., Stevenson, R. D., Behan, W. M., Sloan, D. P., and Horne, C. H. W. (1976). Immunological studies in pre-eclamptic toxaemia. British Medical Journal, 1, 1307-1309.

Tribe, C. R., Smart, G. E., and Mackenzie, J. C. (1974). Pre-eclampsia and the kidney (Letter). British Medical Journal, 2, 335.

Vassalli, P., Morris, R. H., and McCluskey, R. T. (1963). The pathogenic role of fibrin deposition in the glomerular lesions of toxemia of pregnancy. Journal of Experimental Medicine, 118, 467-478.

Velosa, J., Miller, K., and Michael, A. F. (1976). Im- 
munopathology of the end-stage kidney. Immuno- Requests for reprints to: $\mathrm{Dr} \mathrm{C}$. R. Tribe, Department globulin and complement component deposition in of Pathology, Southmead General Hospital, nonimmune disease. American Journal of Pathology, Westbury-on-Trym, Bristol BS10 5NB, UK. 84, 149-160. 